\title{
MANAGING COMPLAINTS TO IMPROVE CUSTOMER PROFITABILITY
}

\section{Abstract:}

In this study, the authors aim to understand whether, to what extent, and under what circumstances, organizational responses to customer complaints improve customer profitability. To do so, they build upon the congruence approach and propose a contingency framework in which the effectiveness of three organizational responses to customer complaints (timeliness, compensation and communications) in improving customer profitability is contingent upon the strength of the relationship and the type of failure. The framework is tested empirically in the financial services industry applying latent class techniques to longitudinal data for a sample of complaining customers. The results reveal that: (1) different complaint-handling initiatives affect customer profitability differently for each of the four segments of complaining customers that are obtained; (2) these heterogeneous responses to complaint handling are explained by differences in the orientation of the relationship and in the failure context; and (3) complaint-handling initiatives are more (less) effective at improving customer profitability when the benefits they offer strongly (poorly) match the benefits sought by customers in each segment to recover from the failure. These results contribute to a better theoretical understanding of customers' heterogeneous responses to complaint handling and offer managerial recommendations to allocate marketing resources across alternative complaint-handling strategies to improve profitability.

Keywords: Customer profitability; Service failure; Complaint handling; Contingency framework; Congruence approach; Latent class modeling. 


\section{INTRODUCTION}

"Unless decision makers fully understand customer complaint behavior and can quantify the return on investment (ROI) of complaint handling, they won't see the link between complaint handling and loyalty and profits, and it's unlikely they will ever allocate adequate resources for change"'(John Goodman, Vice-Chairman of TARP 2006, p.28).

Academics and practitioners continuously warn about the damaging consequences of service failures for the development of successful and profitable customer relationships (Surachartkumtonkun, Patterson, and McColl-Kennedy 2013; Keaveney 1995). However, despite recognizing the benefits of limiting the number of unsatisfactory situations, customer complaints as a result of service failures continue to be the norm, rather than the exception, in most businesses (Zhu, Nakata, Sivakumar, and Grewal 2013; Mittal, Huppertz, and Khare 2008). For example, in the European financial services industry, a recent report shows that, in 2012, complaints increased by 5\%, with 828,040 new reported financial service failures (Data Monitor 2012). In other industries, the pattern is similar, with the European Consumer Centres Network (ECC-Net) reporting a total of 32,197 complaints in electronic commerce in 2012 and an increase of $20 \%$ in the number of complaints in the airlines industry for the same year.

In response to a complaint, firms frequently implement complaint-resolution mechanisms (Huang and Lin 2011; Brady, Cronin, Fox, and Roehm 2008; Hess, Ganesan, and Klein 2003). These strategies imply investing significant financial resources. For instance, at an average cost of handling a customer complaint of \$5 (Goodman 2006), the increase in complaints reported previously in the financial services would lead to a total cost of complaint handling of more than 4 million dollars. However, these investments provide an uncertain return. This is because, as suggested by prior empirical and anecdotal evidence, customers' post-recovery reactions differ significantly (Kaltcheva, Winsor, and Parasuraman 2013; Beverland, Kates, Lindgreen, and Chung 2010; Ringberg, Odekerken-Schröder, and Christensen 2007; Homburg and Fürst 2005; Boshoff 1997), ranging from a magnification of 
the initial negative response to the service failure (Grégoire, Tripp, and Legoux 2009; DeWitt, Nguyen, and Marshall 2008) to improvements in attitudes and perceptions after the failure (Homburg and Fürst 2005; Smith and Bolton 1998). Even the same strategy implemented to compensate customers for a similar failure can be effective for some customers but ineffective for others (Grégoire et al. 2009). Thus, as marketing strives for greater accountability, an important -yet unresolved- challenge for managers is to understand how to allocate resources to the alternative complaint-handling initiatives so that, for each individual customer, the impact on performance outcomes is maximized. Several academic and managerially relevant questions remain to be answered. How do alternative complaint-handling initiatives affect financial performance? Are they equally effective for all complaining customers? If not, under what circumstances does each complaint-resolution mechanism become more effective?

In this study, we attempt to answer these questions and provide managers with new insights to make customer-specific complaint-handling decisions on the basis of an assessment of their potential contribution to customer profitability. To do so, we build on the congruence approach and develop a contingency framework in which the effectiveness of three key organizational responses to customer complaints (timeliness, compensation and communications) in improving profitability is contingent on two critical variables: relationship strength and failure type. Specifically, we propose that achieving a high level of congruence between the benefits offered by firms through complaint handling (economic vs. social benefits) and the benefits sought by customers (economic vs. social benefits) based on the joint consideration of the two contingency variables enhances performance outcome levels. Using data from a financial services company and applying latent class modeling techniques, our proposed framework receives significant support.

This study contributes to existing marketing research in three critical ways. First, prior studies have provided valuable insights into the consequences of complaint handling on 
customer perceptions and attitudes (Kaltcheva et al. 2013; Valenzuela and Cooskey 2012; Beverland et al. 2010). We extend this knowledge by providing an understanding of the financial consequences of complaint handling. To do so, we build a link between complaint handling and profitability that can help practitioners to make more adequate resource allocation decisions on the basis of a financial assessment of alternative complaint-handling initiatives. Second, prior studies have offered preliminary evidence about the heterogeneous nature of customer responses to alternative complaint-resolution mechanisms (Roschk and Gelbrich 2014; Homburg, Fürst, and Koschate 2010; Hess, Ganesan, and Klein 2003). In this study, we not only consider customer heterogeneity explicitly by developing a latent class modeling approach but also offer a theoretical understanding of why different complainthandling initiatives are differently effective at improving profitability. We conceptually propose and empirically show that the nature of the relationship (i.e. relationship strength) and the failure context (i.e. type of failure), by dictating the types of losses experienced by customers, jointly explain their heterogeneous responses to complaint handling. Third, we provide new insights into the circumstances under which recovery efforts are most effective at improving profitability. Building upon the congruence approach (Chandon, Wansink, and Laurent 2000; Mahajan and Churchill 1988), we demonstrate that when the types of benefits offered through complaint handling (economic vs. social) match the types of benefits sought by customers to recover from the loss (economic vs. social), customer profitability is enhanced. Based on these contributions, our study provides a practical basis to help marketers manage complaints to improve customer profitability.

\section{CONCEPTUAL FRAMEWORK AND HYPOTHESES DEVELOPMENT}

In this section, we present a model and a set of testable research hypotheses that describe the effects of organizational responses to customer complaints on customer profitability. The model provides a contingency framework for understanding how relevant 
contingency variables related to the customer-firm relationship (i.e. relationship strength) and the failure context (i.e. failure type) influence customer responses to complaint-handling activities after a service failure. Drawing upon the congruence approach, the conceptual model proposes that the effectiveness of complaint handling depends on the match (or mismatch) between the nature of the benefits provided by the firm and the nature of the benefits sought by the customer in the complaint-handling process. The framework is presented in Figure 1.

-- Insert Figure 1 about here --

When a service failure occurs, the customer experiences a loss due to the failure and the relationship becomes unbalanced. Because customers are motivated to seek balance (a foundational schema, as denoted by Ringberg et al. (2007)), they frequently file complaints and companies, in response to them, can initiate a service-recovery strategy aimed at providing a gain to the customer to counteract the loss caused and restore the equality in the exchange relationship. To provide a gain to the customer, the firm can engage in a variety of recovery efforts (Grewal, Roggeveen, and Tsiros 2008; Davidow 2003; Estelami 2000). In this study, we focus on three key complaint-handling activities: timeliness, compensation, and communications. These three activities fall into the three categories of organizational responses identified by Gelbrich and Roschk (2011) and by Estelami (2000). Importantly, as we will discuss later in more detail, these initiatives provide different types of benefits to customers to restore the balance in the relationship: economic vs. social benefits (Berry 1995). Also, as noted by Smith, Bolton, and Wagner (1999, p. 358), these three activities "are particularly salient to customers, are easily acted on by managers" and have received considerable attention in the academic literature (Estelami 2003).

Implementing these complaint-handling activities, however, produces highly heterogeneous responses from customers (Beverland et al. 2010; Homburg, Fürst, and 
Koschate 2010; Smith et al. 1999; Smith and Bolton 1998). We argue that this variation in the responses to complaint handling is not random. Instead, it is driven by relevant variables. Therefore, our conceptual framework is a contingency approach which proposes that we can observe wide variations in customer responses to complaint handling and that this variation can be explained by identifying relevant contingency variables. In this study, and consistent with prior research (Grégoire, Tripp, and Legoux 2009; Smith, Bolton, and Wagner 1999), we believe that the customer relationship and the failure context are critical elements that can potentially explain the differences in customer responses to complaint-handling efforts. We consider relationship strength as a central relationship-related characteristic (Homburg, Fürst, and Koschate 2010) and failure type as a critical failure context aspect (Smith, Bolton, and Wagner 1999). In addition to having received considerable support in prior research as moderators of complaint handling (Kaltcheva et al. 2013; Ringberg et al. 2007), these two variables help us to understand the types of resources that customers lose in a failure episode: economic vs. social resources (Smith, Bolton, and Wagner 1999). In our framework, we propose that these two contingency variables act together in affecting the types of losses that customers experience and, thus, will jointly explain the heterogeneous responses to complaint handling.

The existence of different types of benefits provided by alternative complaint-handling activities (economic vs. social) and different types of losses that customers experience during a failure situation (economic vs. social) provides the basis for the development of a congruency framework (Chandon, Wansink, and Laurent 2000).

\section{A congruency framework of complaint handling effectiveness}

To understand the differences in customer reactions to complaint handling under different values of the contingency factors, we build on the congruence approach which describes the relationships between factors and the resulting outcome levels (Mahajan and 
Churchill 1988). In our study, we focus on customer profitability, or the difference between customer revenues and costs, as the financial outcome variable. According to the congruence approach, when two factors match (e.g. benefits provided by the firm through complaint handling and benefits sought by the customer to recover from the losses), outcome levels (e.g. customer profitability) will be enhanced or be greater than when the two factors are mismatched (Mohr and Nevin 1990). This idea is also implicit in the resource exchange theory which suggests that individuals assign more value to exchanges of similar categories of resources than to exchanges of dissimilar categories (Roschk and Gelbrich 2014; Smith et al. 1999). Applied to a service failure context, the congruence approach suggests that the probability of the customer responding favorably to the complaint-handling initiatives implemented by the firm depends on the degree to which the nature of the benefits provided through the recovery efforts match the nature of the benefits sought by the customer (as determined by the two contingency factors: relationship strength and failure type). A strong match will increase the probability of the customer perceiving that the loss produced by the service failure is offset with a gain of the "same kind", leading to a higher perceived value and to enhanced outcome levels (i.e. customer profitability). A poor match, in contrast, will result in the perception that the loss is not compensated properly with gains of a "different kind" and that the actions taken are not sufficient to offset the loss incurred.

Below, we describe, in order, the types of benefits provided by alternative complainthandling activities and the types of losses experienced by customers during a failure situation -and the types of benefits sought to recover from these losses- under different values of the contingency variables. We then apply the logic of the congruency framework and develop a set of testable research hypotheses.

Benefits provided by complaint handling 
Complaint handling aims to provide customers with gains to counterbalance the losses they suffered in the failure episode. However, different complaint-handling initiatives provide different types of benefits which can be classified into the following two categories: economic and social (Berry 1995). Economic benefits represent material or tangible incentives (e.g. product replacements, refunds, time savings) and social benefits involve symbolic, psychological, or emotional gains (e.g. making the customer feel that the firm cares, providing apologies and explanations). As noted previously, in this research, we focus on three complaint-handling activities: timeliness, compensation, and communications. Here, we discuss the type/s of benefits that each of these activities provides to customers in a complaint-handling situation.

Timeliness. Timeliness refers to the speed with which an organization responds to or handles a complaint (Liao 2007; Davidow 2003) and it provides both economic and social benefits. Quick responses provide economic benefits by helping to increase the efficiency of the complaint-handling process and saving additional economic resources and effort on the part of the customer. At the same time, quick responses also provide social benefits because they make the customers feel that the firm cares about them and is being attentive. As noted by Ringberg et al. (2007) and Davidow (2003), fast responses serve as signals that customers are appreciated and being cared for by the firm. In addition, responding quickly helps restore the social bonds between the parties by reestablishing the feelings of respect and the customers' self-esteem (Johnson, Matear, and Thomson 2011).

Compensation. Compensation involves refunds, price discounts, product replacements, repairs and payment of additional expenses that organizations provide to complaining customers after a service failure (Kelley, Hoffman, and Davis 1993). As noted by Estelami (2000), material compensatory measures, by increasing the economic gains of the customer, help improve the output-to-input ratio in the relationship (internal equity) as well as 
the balance between the output-to-input ratio of the customer and that of the company (external equity). Thus, by offering material incentives, compensation provides economic benefits to customers to offset the loss produced by the service failure.

Communications. Communications refer to apologies and post-failure explanations provided by the firm regarding the reasons for the failure and its solution (Van Vaerenbergh, Lariviere, and Vermeir 2012; Gelbrich 2010). By admitting the firm's mistake and offering the customer a sincere apology and an explanation, communications provide customers with social benefits. As emphasized by Smith, Bolton, and Wagner (1999), these activities "communicate respect and empathy (social resources) to the customer" (p. 360). These actions, thus, reduce the emotional distress and suffering caused by the failure and contribute to validating the customer's sense of importance and self-esteem after a service failure (Johnson, Matear, and Thomson 2011).

Types of losses experienced and benefits sought by customers: The joint moderating effect of relationship strength and type of failure

In a failure episode, customers can experience two different types of losses: economic and/or social (Smith, Bolton, and Wagner 1999). We argue that the type/s of losses experienced by customers and, thus, the type/s of benefits sought by them to recover from the losses, are going to be determined by the joint impact of the two contingency variables that we study in this research: relationship strength and failure type.

Relationship strength. Relationship strength is the extent, degree, or magnitude of the association between the customer and the service provider (Barnes 1997). Strong relational customers hold a "strong desire to maintain emotional ties with the provider, even in the face of adverse events" (Ringberg et al. 2007, p. 197). For these customers, the failure is a social rupture that can lead to emotional distress and disequilibrium, producing negative emotions such as disappointment, feelings of being hurt and frustration (Johnson, Matear, and Thomson 
2011; Ringberg et al. 2007), and causing serious damage to the customer's sense of importance and self-esteem (Johnson, Matear, and Thomson 2011). When a service failure occurs, these customers focus not on the failure itself but on the breakdown in the relational aspect of the exchange. As noted by Ringberg et al. (2007), for customers with strong relationships, the complaint-handling process should center "not on restitution or product replacement but rather on reestablishing an emotional bond with the provider" (p. 197). Customers in a weak relationship, in contrast, do not perceive failures as relational or personal damage. Instead, they adopt a more utilitarian and rational view of the relationship and focus on "the material aspects of the dispute" (Beverland et al. 2010, p. 620). These customers frame the failure situation in terms of performance standards, or the economic and timerelated inconveniences that it generates, and search for ways to counterbalance them. As Beverland et al. (2010) note, "solving the problem and/or gaining some form of restitution" (p. 624) is important for customers characterized by a rational appraisal in the relationship. These differences in the types of losses experienced by strong (social losses) and weak (economic losses) relationship customers after a service failure will lead to differences in the benefits they seek in complaint handling: strong relationship customers will seek social gains, and weak relationship customers will pursue economic gains.

Type of failure. The type of failure refers to the different losses that customers can experience in service failure episodes. In line with the work of Gelbrich and Roschk (2011), we identify two main types of service failures: economic and non-economic. Economic failures refer to situations such as defective and malfunctioning products or mistakenly charging a superior price for a product or service, and they produce financial or material losses for the customer. In these situations, customers tend to adopt "conflict styles conducive to gaining practical outcomes" (Beverland et al. 2010, p. 620). Non-economic failures, on the other hand, involve episodes such as long waiting times, rude treatment by the personnel, or 
lack of attention, and represent non-material and symbolic losses to the customer who experiences the failure. Customers who suffer non-economic failures search for symbolic benefits, as exemplified by an informant in the study of Beverland et al. (2010) who, after suffering a non-economic failure (his/her group of friends was split up in the cinema), said: "I have forgiven them... like I said, the important thing is they've acknowledged it and said "hopefully it won't happen next time" and they have explained their side of the situation" (p. 620-622). These differences in the types of losses experienced by customers under economic and non-economic failures will lead to differences in the benefits they seek in complaint handling: customers suffering economic failures will seek economic gains and customers suffering non-economic failures will pursue social gains.

Joint moderating effect of relationship strength and failure type. We argue that the two contingency variables that we consider, relationship strength and failure type, will act jointly to determine the types of losses experienced by customers. When we combine the two contingency variables, we obtain four different situations or segments: (1) strong relationship customers who suffer an economic failure (SR-EF), (2) strong relationship customers who suffer a non-economic failure (SR-NEF), (3) weak relationship customers who suffer an economic failure (WR-EF), and (4) weak relationship customers who suffer a non-economic failure (WR-NEF). These four segments differ in the types of losses that customers suffer and, thus, in the types of benefits that they will seek to recover from the losses. In segments 2 (SR$\mathrm{NEF}$ ) and 3 (WR-EF), customers only experience one type of loss: a social loss and an economic loss, respectively. Thus, customers in these two segments will primarily pursue social (segment 2) and economic (segment 3) benefits to recover from the losses caused by the failure. In contrast, customers in segments 1 (SR-EF) and 4 (WR-NEF) experience the two types of losses: economic and social. Therefore, these customers will seek both types of benefits: economic and social. However, we argue that the importance -weight- that 
customers in these two segments will attach to each type of loss and, thus, the strength with which the two types of benefits will be sought, might not be the same.

Research in complaint handling suggests that individuals attach greater value to aspects related to the sense of self, such as the customer relationship, than to aspects that are more superficial and situation-specific, such as the context of a failure episode, or "peripheral to the sense of self" (Ringberg et al. 2007, p.196). This is consistent with theories about the way in which individuals make judgments in the presence of multiple information sources (Slovic and Lichtenstein 1971). When confronted with various pieces of information (e.g. types of losses), "high-scope cues", which have developed over time and are not easily changed (e.g. relationship variables), are more reliable and diagnostic in making judgments than "low scope cues", which are transient and situation-specific (e.g. a failure situation) (Purohit and Srivastava 2001). Thus, losses that emerge from framing the failure in terms of a breakdown in the relationship will be more diagnostic and given a greater weight than losses derived from framing it in terms of the specific failure context.

Thus, although customers in segments 1 (SR-EF) and 4 (WR-NEF) experience both social and economic losses, we expect that they will place greater weight on the losses associated with the relationship-related aspect (i.e. the strength of the relationship), and less on the losses related to the situation-specific failure context (i.e. the type of failure). That is, we argue that customers in segment 1 (SR-EF) will weigh the social loss (related to the strength of the relationship) more heavily than the economic loss (associated with the type of failure) while customers in segment 4 (WR-NEF) will weigh the economic loss (related to the strength of the relationship) more heavily than the social loss (associated with the type of failure). Therefore, customers in segment 1 (SR-EF) will seek both types of benefits but they will value social benefits more strongly than economic benefits. Customers in segment 4 
(WR-NEF) will seek both types of benefits but they will value economic benefits more strongly than social benefits.

\section{Research hypotheses}

In the prior discussion, we have identified the types of benefits (economic, social, or both) that the three complaint-handling initiatives that we study (i.e. timeliness, compensation and communications) provide to customers. We have also identified the types of losses (i.e. economic, social, or both) that customers can experience in a failure situation on the basis of the joint impact of the two contingency variables (i.e. relationship strength and failure type). In this section, we build upon the congruency framework to develop a set of testable research hypotheses. Table 1 offers a summary of our hypotheses.

-- Insert Table 1 about here --

We begin by offering a general prediction about the impact of complaint handling on customer profitability. In line with prior research (Gelbrich and Roschk 2011; Homburg and Fürst 2005; Davidow 2003), we expect that, regardless of the level of the contingency variables, organizational responses to customer complaints will produce a positive reaction on the customer that will lead to an increase in customer profitability.

H0: Timeliness, compensation, and communications will positively influence customer profitability.

In this research, we are concerned with providing a theoretical understanding of the degree to which organizational responses to customer complaints are more or less effective at improving customer profitability under different values of the contingency variables. According to the congruency framework (Chandon, Wansink, and Laurent 2000; Mahajan and Churchill 1988), we expect that outcome levels (i.e. customer profitability) will be determined by the level of congruence between the benefits (social vs. economic) provided by alternative organizational responses to customer complaints and the benefits (social vs. 
economic) sought by customers in the four segments that are identified (based on a customer's relationship orientations -strong vs. weak relationships-, and the type of failure suffered -economic vs. non-economic). Specifically, when the level of congruency is high (strong match between the benefits provided and the benefits sought), we expect outcome levels to be higher than when the level of congruency is low (poor match between the benefits provided and the benefits sought). Below we derive the hypotheses for each of the four segments.

\section{Segment 1: Strong relationship and economic failure (SR-EF)}

Customers in this segment experience both economic and social losses. Thus, timeliness, which provides economic and social benefits, will produce a strong match with the benefits sought by these customers, leading to enhanced performance outcomes. As noted, we expect these customers to weigh the social losses that they experience (because of the strength of the relationship) more heavily than the economic losses (because of the type of failure), which leads us to expect a stronger effect of communications than of compensation on profitability. More formally,

H1: For customers with a strong relationship experiencing an economic failure (segment 1, SR-EF), the effect of complaint handling on customer profitability will be stronger for (1) timeliness, followed by (2) communications, and by (3) compensation.

\section{Segment 2: Strong relationship and non-economic failure (SR-NEF)}

Customers in segment 2 experience social losses. We expect communications, which provide social benefits, to be completely congruent with the benefits sought by these customers, producing enhanced performance outcomes. Timeliness, which provides social and economic benefits, will produce moderate congruity, while compensation, which only provides economic benefits, will result in a poor match with the benefits sought by these customers. We hypothesize, 
H2: For customers with a strong relationship experiencing a non-economic failure (segment 2 SR-NEF), the effect of complaint handling on customer profitability will be stronger for (1) communications, followed by (2) timeliness, and by (3) compensation.

\section{Segment 3: Weak relationship and economic failure (WR-EF)}

Customers in segment 3 experience economic losses. We expect compensation, which provides economic benefits, to be highly congruent with the benefits that these customers are seeking. Timeliness, which provides economic and social benefits, will produce moderate congruity, while communications, which only provides social benefits, will not produce a good match with the benefits sought by these customers. Hence,

H3: For customers with a weak relationship experiencing an economic failure (segment $3 \mathrm{WR}-E F$ ), the effect of complaint handling on customer profitability will be stronger for (1) compensation, followed by (2) timeliness, and by (3) communications.

\section{Segment 4: Weak relationship and non-economic failure (WR-NEF)}

Customers in segment 4 experience economic and social losses. Timeliness, which provides economic and social benefits, will produce a strong match with the benefits sought by these customers, leading to enhanced performance outcomes. As discussed previously, these customers will place greater weight on the economic losses (related to the strength of the relationship) and less on the social losses (associated with the type of failure), which leads us to expect a stronger effect of compensation than of communications on customer profitability. More formally,

H4: For customers with a weak relationship experiencing a non-economic failure (segment $4 \mathrm{WR}-\mathrm{NEF}$ ), the effect of complaint handling on customer profitability will be stronger for (1) timeliness, followed by (2) compensation; and by (3) communications.

\section{Effectiveness of complaint handling across segments}


In addition to providing an understanding of the effectiveness of complaint handling within the four segments identified, we follow the previous line of reasoning and derive some theoretical predictions about the effectiveness of complaint handling across the four segments. As noted, timeliness is expected to be highly congruent with the benefits sought by customers in segments 1 and 4, which leads us to expect a stronger effect of this initiative on profitability for these segments than for segments 2 and 3. We argued that compensation would produce a perfect match with the benefits sought by customers in segment 3 and a good match with the benefits sought by customers in segment 4 , leading us to expect a stronger effect of compensation on profitability for these two segments than for segments 1 and 2 . Finally, with regard to communications, the match between this initiative and the benefits sought by customers is very strong for those belonging to segment 2 , followed by customers in segment 1, which leads us to expect a stronger effect of communications on profitability for these segments than for segments 3 and 4 . Formally,

H5: The effectiveness of each complaint-handling initiative will vary across segments: a) The effect of timeliness on customer profitability will be stronger for customers in segments 1 and 4 than for customers in segments 2 and 3.

b) The effect of compensation on customer profitability will be stronger for customers in segments 3 and 4 than for customers in segments 1 and 2.

c) The effect of communications on customer profitability will be stronger for customers in segments 2 and 1 than for customers in segments 3 and 4.

\section{RESEARCH METHODOLOGY}

In this section, we develop an econometric model to empirically test the proposed conceptual framework and its associated hypotheses. To choose the appropriate model for estimating the relationships, we must first deal with the following three modeling challenges. First, we want to investigate the effect of the categories of variables discussed above on 
customer profitability in the context of a service failure. To ensure that the analysis provides reliable information about the true impact of the variables studied on profitability, it is important for our dependent variable to reflect the change in the level of customer profitability before and after the service failure. Thus, we develop a difference model in which our dependent variable is the difference between customer profitability after the customer complaint and customer profitability before the customer complaint.

Second, as noted previously, in the context of service recovery, we deal with heterogeneous customers who may respond differently to alternative complaint-handling efforts. This implies that, when confronted with a specific complaint-handling initiative, customers may behave differently, resulting in different levels of profitability. Our model must explicitly take customer heterogeneity (both observed and unobserved) into account in order to provide robust results and increase their practical usefulness for managing complaints in a customized way. In our model, we account for unobserved heterogeneity by estimating a latent class model, which is an especially powerful tool for understanding how the effect of the explanatory variables on profitability differs across segments. The latent class model assumes that the parameters might differ between a priori unknown underlying segments. To predict the probability of latent class membership, we include the two contingency variables (relationship strength and failure type) which, as the conceptual part of the manuscript suggests, are critical for understanding customers' heterogeneous responses to complaint handling. This allows us to take observed heterogeneity into account.

Third, given our interest in understanding the effect of organizational responses to customer complaints on customer profitability, and that the change in our dependent variable, customer profitability, may be the result of changes in other variables, we should control for the effect of these additional factors in order to isolate the effects of our focal variables and ensure that we identify their true impact on profitability. Thus, in our model, in addition to 
introducing the categories of variables discussed above, we control for the effect of additional relevant variables in the explanation of customer profitability by including customer profitability before the failure, targeted marketing activities, and a set of demographic variables (Venkatesan and Kumar 2004).

To tackle the key modeling challenges described, we estimate a latent class linear regression model. Let $\mathrm{S}$ be the number of segments $(\mathrm{s}=1,2, \ldots, \mathrm{S})$, each consisting of an a priori unknown number of individuals that are homogeneous with respect to their responsiveness to complaint handling. Profitability for customer $\mathrm{i}\left(\mathrm{Cprof}_{\mathrm{i}}\right)$ is defined as a weighted sum of the distribution of the dependent variable given individual i's class membership s and a set of individual-specific predictor variables. For a segmentation to be actionable, it is necessary to characterize the segments according to relevant variables (Gupta and Chintagunta 1994). In our model, the probability that individual $\mathrm{i}$ belongs to segment $\mathrm{s}$ is a function of the two contingency variables identified in the conceptual framework: relationship strength and failure type. This will allow us to classify individuals into segments on the basis of these characteristics. The latent class model can be represented as follows:

CProf $_{i}=\sum_{s=1}^{S} P\left(s \mid\right.$ RelStrength $_{i}$, FailureType $\left._{i}\right) * f\left(\right.$ CProf $_{i} \mid s$, ComplHand $_{i}$, Controls $\left._{i}\right)$ where $P$, the probability of belonging to class $s$, is a function of the two contingency variables (mixing weights): the strength of the relationship (RelStrength $)_{i}$ and the type of failure (FailureType (F) $_{\text {; }}$ and $f$ denotes how the dependent variable is distributed given a customer's class membership $s$ and the values of the predictor variables for that customer (complaint handling -ComplHand, and control variables - Controls $\left._{i}\right)$.

The parameters are estimated using Maximum Likelihood (ML). The likelihood function is derived from the probability density function defined in the previous equation, and can be represented as follows: 


$$
L L=\sum_{i=1}^{N} \log f\left(\text { CProf }_{i} \mid \text { RelStrength }_{i}, \text { FailureType }_{i}, \text { ComplHand }_{i}, \text { Controls }_{i}, \beta\right)
$$

where, $N$ is the total number of individuals in the sample; and $f$ is the probability density associated with customer $\mathrm{i}$ given parameter values $\beta$ (which include both the parameters that measure the impact of complaint handling on profitability and the parameters that measure the effect of the contingency variables on the probability of belonging to class s). To estimate our proposed model, we employ Latent Gold 4.5.

\section{DATA}

\section{Study Context}

We test our conceptual framework in the financial services industry. Mistakes and failures in the delivery of banking services are frequent occurrences (Lewis and Spyrakopoulos 2001). The European Consumer Centres Network (2012) finds that the number of complaints in banking is growing. The same conclusion is reached by EPSI Rating (2012), a project developed by several European business schools which highlights that, in addition to an increasing number of complaints from bank users, there is a high percentage of customers (up to 33\%) who consider that their complaint has remained unresolved. These results generate distrust among consumers and require greater efficiency in the resolution of service failures and a fair and transparent financial service. Moreover, the international financial system currently faces great uncertainty resulting from both zero economic growth prospects in the short term and the problems of European banks to obtain funding. Thus, resources invested by companies in marketing actions should be allocated to profitable alternatives to generate growth and a good return on their investment. Given the large amount of resources devoted to complaint handling in this context of increasing complaints, it is important for firms to manage them optimally in order to increase customer profitability.

\section{Dataset and Variable Measurement}


In this research, we use data from a major bank in a European country. The bank sells financial products in different categories (e.g. certificates of deposit, savings accounts, mortgages) to individual customers (B2C). As in most financial services companies, this bank commits mistakes that produce service failures and these failures can result in customer complaints. For this study, the financial services company provided a sample of customers who had experienced a service failure and filed a complaint between June 2007 and July 2011. After removing customers with incomplete information or missing values in some of our key variables, we have an effective sample size of 791 complaining customers. For these customers, we have access to two sets of information: (1) complaint-related data, which offers information about the customer complaint and the company response, including the date of the complaint, the organizational response (timeliness, compensation, communications), and the motives of the complaint as indicated by the customer; and (2) transactional data, which includes customer profitability (the difference between customer revenues and costs), targeted marketing activities, and additional customer-level information (including demographics). We merged these two sources of information and created a comprehensive longitudinal dataset to study the proposed relationships.

Because we are interested in the changes in customer profitability before and after the service failure, for each customer in the sample, from the initial observation window of 4 years, we considered only a reduced observation window of 2 years to empirically estimate our model. Specifically, we looked at the date of the customer complaint and obtained information 12 months before and 12 months after the complaint. Figure 2 shows the graphical representation of the longitudinal data for the analyses.

-- Insert Figure 2 about here --

We believe that one year is an adequate and conservative period for computing the measures of our focal variables for the validation of the model, both before the complaint and 
after the complaint. Before the complaint, we need to go back in time to ensure that customer behavior was not already affected by a service failure that had occurred or started some time before the complaint was filed. After the complaint, we also need to go forward in time to ensure that the change in behavior and profitability is persistent and not only temporary. Because we control for other drivers of profitability in our model, this strategy helps us derive robust and valid results for the effect of the variables studied.

The variables that we study and their associated measures are displayed in Table 2 along with a set of selected descriptive statistics. To carry out the empirical analysis, the variables were standardized in order to enable parameter comparisons. Table 3 provides the correlation matrix.

-- Insert Tables 2 and 3 about here --

\section{ESTIMATION RESULTS}

In this section, we present the estimation results and test the proposed hypotheses. As noted previously, we estimate a latent class model to control for unobserved customer heterogeneity because it allows the model parameters to vary across a priori unknown customer segments (Dias and Vermunt 2007; Wieringa and Verhoef 2007). To identify the number of segments in our empirical application we use information criteria. In Table 4, we report the Bayesian Information Criterion (BIC) and the Akaike Information Criterion with a per parameter penalty factor of three (AIC3), which are computed using information about the log-likelihood of the model (also reported in the table) in relation to the number of parameters estimated. The lower the value of these information criteria, the better the fit of the model to the data. An inspection of the information criteria in Table 4 shows that the BIC favors a three-segment solution while the AIC3 reaches its minimum for a four-segment solution. Similar to Wieringa and Verhoef (2007), we decided to select the four-segment solution provided by AIC3 because it is the best segment retention criterion for a large variety of data 
configurations. This is consistent with Andrews and Currim (2003), who conclude that the Akaike Information Criterion with the per parameter penalty factor of three rather than the traditional factor of two is the best segment criterion. In addition, it is also consistent with our theoretical development, which distinguishes between four different segments on the basis of the joint impact of the two contingency variables.

-- Insert Table 4 about here --

Table 5 shows the parameter estimates for the latent class model with a four-segment solution. In terms of model fit statistics, compared with a model that does not consider unobserved customer heterogeneity (standard linear regression model), the four-segment latent class model improves the $\mathrm{R}^{2}$ substantially (0.81 vs. 0.10$)$. This result offers additional evidence for the heterogeneous nature of customer responses to complaint handling (Homburg, Fürst, and Koschate 2010; Ringberg et al. 2007), and it demonstrates that failing to account for unobserved customer heterogeneity may lead to incorrect and unreliable estimated parameters. In addition, we provide the Wald test, which indicates, for each explanatory variable, whether the estimated coefficients for the segments are significantly different.

-- Insert Table 5 about here --

The four segments identified can be characterized on the basis of the two contingency variables that we consider, relationship strength and failure type, and they correspond to the four segments discussed in the theoretical part of the study. The results show that the probability of a customer belonging to segment 1 (SR-EF) is strongly influenced by relationship strength $(\beta=0.57)$ and positively related to suffering an economic failure $(\beta=$ 0.19). This segment makes up $17.2 \%$ of the sample (136 complainants), the average relationship strength is 29.66 years, and the type of failure that dominates is economic (66\% percent of customers in this segment suffer this type of failure). Customers in segment 2 (SR- 
$\mathrm{NEF})$ are characterized by having a strong relationship with the firm $(\beta=0.30)$ and having suffered a non-economic failure $(\beta=0.27)$. For customers in this segment, which represents $35.7 \%$ of the sample ( 282 customers), the average relationship strength is 22.67 years, and the dominating type of failure is non-economic (56\% of customers). The probability of belonging to segment 3 (WR-EF) is weakly affected by relationship strength $(\beta=0.16)$ and positively related to suffering an economic failure $(\beta=0.11)$. The average relationship strength in this segment (representing $38.9 \%$ of the sample, with 308 customers) is 21.55 years, and the type of failure that prevails is economic (69\% of customers). Finally, segment 4's members (WRNEF) are characterized by having a weak relationship with the firm $(\beta=0.09)$ and having suffered a non-economic failure $(\beta=0.08)$. This segment is the smallest $(8.2 \%$ of the sample, with 65 customers), with an average relationship strength of 14.23 years and a dominating role of non-economic failures (53\% of customers).

In Table 5, a positive parameter indicates a positive impact of the corresponding variable on the change in customer profitability (customer profitability increases). In general, as we can see from the table, we find significant support for our proposed model because all but one of the complaint-handling parameters are significant from a statistical point of view. ${ }^{1}$ In addition, we find significant heterogeneity across segments in the strength of the associations. Consistent with our proposed contingency framework, we describe below the results for the joint moderating effect of relationship strength and failure type and test the proposed hypotheses.

Before testing our core hypotheses $(\mathrm{H} 1-\mathrm{H} 4)$, we begin by testing our general prediction about the positive effect of complaint handling on customer profitability (H0).

\footnotetext{
${ }^{1}$ We estimated the model with service usage and cross-buy, two central components of customer profitability (Bolton, Lemon, and Verhoef 2004; Venkatesan and Kumar 2004; Reinartz and Kumar 2003), as dependent variables and the results are consistent with the findings for the customer profitability model. We also estimated the model using the percentage change in customer profitability, instead of the absolute change. The substantive results of our study remain unchanged.
} 
Overall, the results offer support for our initial hypothesis, as most of the parameters (11 out of 12) are significant from a statistical point of view, and all but one are positive. We only found a negative parameter for the effect of compensation in segment 2 (SR-NEF), which is discussed later in more detail. $\mathrm{H} 0$ is, thus, generally supported by the data.

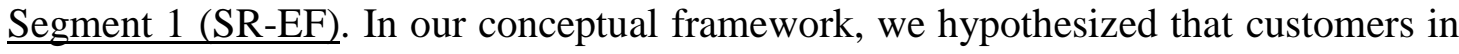
segment 1 (having a strong relationship and suffering an economic failure), after experiencing both social and economic losses, would seek both types of benefits to recover from the losses. These customers were also expected to attach more weight to the social loss they suffer (because of the strong relationship that they maintain with the company) than to the economic loss (associated with the economic failure suffered). Thus, we expected timeliness to have the strongest impact on profitability, followed by communications and then by compensation. The results show that customer profitability after the complaint is positively and strongly affected by timeliness $\left(\beta_{\mathrm{s} 1}=4.27\right)$, followed by communications $\left(\beta_{\mathrm{s} 1}=2.76\right)$, and by compensation $\left(\beta_{\mathrm{s} 1}=0.30\right){ }^{2}$ These results provide support for $\mathrm{H} 1$.

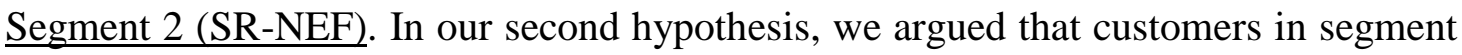
2 (having a strong relationship and suffering a non-economic failure), after experiencing social losses, would seek social benefits to recover from the losses. Thus, we hypothesized that communications would have the strongest impact on profitability, followed by timeliness (which also provides social benefits) and then by compensation. In support of $\mathrm{H} 2$, the results show that customer profitability after the complaint is strongly affected by communications $\left(\beta_{\mathrm{s} 2}=2.54\right)$, followed by timeliness $\left(\beta_{\mathrm{s} 2}=0.25\right)$, and finally by compensation $\left(\beta_{\mathrm{s} 2}=-1.33\right)$. The negative effect of compensation on profitability for customers in segment 2 might appear surprising. However, prior research has suggested that customers who frame the failure

\footnotetext{
${ }^{2}$ In all the reported results, the differences between the parameters are statistically significant, unless otherwise stated.
} 
situation in terms of social losses because of their strong bonds with the firm may respond weakly to compensation. For example, Hess, Ganesan, and Klein (2003) note that customers with strong relationships demand less immediate compensation "because they consider the balance of equity across a longer horizon of exchanges" (p. 140). In the same line, Grégoire, Tripps, and Legoux (2009) show that increasing compensation to customers in a strong relationship after a service failure does not provide increasing returns. More notably, these responses can even become negative. This is shown, for example, in a passage from one of the informants in Beverland et al. (2010)'s study, who was very angry with the economic incentives offered in an interpersonal (relational) dispute: "The owner knows what I said, and started giving me discounts to make me stay, but he's just money, money, nothing else" (p. 626). Thus, providing economic benefits to customers that seek social benefits may produce a negative reaction.

Segment 3 (WR-EF). Customers in segment 3 (having a weak relationship and suffering an economic failure) experience economic losses. Thus, according to the congruence approach, they will seek economic benefits to recover from the losses. This would imply, as we hypothesized (H3), that compensation (which provides economic benefits) would have the strongest impact on profitability, followed by timeliness (which in addition to social benefits also provides economic benefits) and communications. In support of $\mathrm{H} 3$, the results reveal that customer profitability after the complaint is positively and strongly affected by compensation $\left(\beta_{\mathrm{s} 3}=17.21\right)$, followed by timeliness $\left(\beta_{\mathrm{s} 3}=7.60\right)$, and then by communications $\left(\beta_{\mathrm{s} 3}=2.24\right)$.

Segment 4 (WR-NEF). Our fourth hypothesis was concerned with customers in segment 4 (having a weak relationship and suffering a non-economic failure) who experience both economic and social losses. According to the congruence approach, these customers were expected to seek both types of benefits, economic and social. At the same time, they 
were expected to weigh the two types of benefits differently, attaching a disproportionate value to economic benefits that help compensate the economic losses caused by framing the failure in terms of the weak relationship that they maintain with the firm. As noted in $\mathrm{H} 4$, we expected timeliness to have the strongest impact on profitability, followed by compensation, and finally by communications. The results show that customer profitability after the complaint is positively affected by compensation $\left(\beta_{\mathrm{s} 4}=0.41\right)$, followed by timeliness $\left(\beta_{\mathrm{s} 4}=\right.$ 0.23). Communications, however, do not significantly affect profitability for customers in this segment $\left(\beta_{\mathrm{s} 4}=0.31 ; \mathrm{p}>0.10\right)$. Thus, only initiatives that provide economic benefits (i.e. compensation and timeliness) seem to be effective for customers in this segment, which is in line with our arguments about the stronger weight that they would attach to the economic losses associated with the weak relationship that they maintain with the firm. Hence, these results provide only weak support for our fourth hypothesis.

Effectiveness of complaint handling across segments. In our fifth hypothesis, we argued that the effectiveness of complaint handling could vary across the four identified segments. We expected timeliness to be more effective at improving profitability for segments 1 and 4. The results, however, show that timeliness is more effective for customers in segment $3\left(\beta_{\mathrm{s} 3}=7.60\right)$, followed by customers in segment $1\left(\beta_{\mathrm{s} 1}=4.27\right)$. This finding suggests that, although timeliness does not offer the best match with the benefits that customers in segment 3 seek, it can have a stronger impact on profitability than for other segments in which there is a higher level of congruence between this initiative and the benefits sought by their customers. This result can be especially valuable for companies that have established specific complaint-handling protocols, aiding them in optimal resource allocation decisions (as we discuss in the managerial implications section). Compensation was expected to be very effective at improving profitability for customers in segments 3 and 4 . The results offer support for $\mathrm{H} 5 \mathrm{~b}$, as compensation has the strongest impact on profits for 
customers in segment $3\left(\beta_{\mathrm{s} 3}=17.21\right)$, followed by customers in segment $4\left(\beta_{\mathrm{s} 4}=0.41\right)$. Finally, communications was expected to impact profitability more strongly for customers in segments 2 and 1. In line with these expectations, the results show that communications has the strongest impact for customers in segments 1 and $2\left(\beta_{\mathrm{s} 1}=2.76 ; \beta_{\mathrm{s} 2}=2.54\right)$. However, the magnitude of the effects is not statistically different from the impact of communications on profitability for customers in segment 3 ( $\beta_{s 3}=2.24$ ), offering only mixed support for H5c.

-- Insert Table 6 about here --

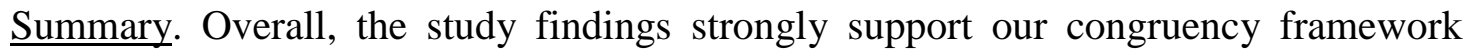
(Table 6 offers a summary of the hypothesis testing results). After experiencing different types of losses in the failure situation, customers seek benefits of the same kind to recover from the losses. In line with our theory, complaint-handling initiatives that provide customers with benefits that match the losses experienced have proven much more effective at increasing profitability than other initiatives that do not directly address the losses that customers experience. As our results show, when customers experience either social losses (segment 2 SR-NEF) or economic losses (segment 3 WR-EF), offering social (communications) and economic (compensation) benefits, respectively, is strongly effective at improving profitability. Notably, we find that the effectiveness of complaint handling becomes weakened (or even generates a negative reaction) when the benefits it provides do not match the benefits sought by customers (e.g. effect of compensation for segment 2).

An interesting situation from the joint moderating effect of the contingency variables emerges when customers experience both types of losses (economic and social). Building on prior complaint-handling research and on theories about judgment in the presence of multiple information sources, we argued that customers would attach more weight to losses produced by framing the failure in terms of the strength of the relationship, than to losses produced by framing it in terms of the failure context. We found strong support for this. Furthermore, the 
results show that, for one segment (segment 4 WR-NEF), customers only respond to complaint-handling initiatives that offer the dominating type of benefit sought (i.e. economic benefits). And they respond even more strongly if these benefits are provided in isolation (i.e. compensation, which only provides economic benefits) than when they are provided together with social benefits (i.e. timeliness, which provides economic and social benefits). Finally, our study also offers a comparison of the strength of the effects across segments, showing that in certain situations firms can obtain a larger return on their investment by implementing complaint-handling initiatives in specific segments despite not being completely congruent with the benefits that customers are seeking.

\section{THEORETICAL IMPLICATIONS}

In this research, we have tried to provide a conceptual framework for managing complaints to increase profitability. In the proposed framework, we describe and analyze whether, to what extent, and under what circumstances, organizational responses to customer complaints improve customer profitability. We empirically test the framework in the financial services industry and the study findings enable us to contribute to existing marketing literature in several critical ways.

Whether. In this study, we demonstrate that organizational responses to customer complaints can improve customer profitability. While prior research has widely investigated the implications of complaint handling in terms of customer attitudes, perceptions and intentions towards the relationship (Gelbrich 2010; Estelami 2003; Tax, Brown, and Chandrashekaran 1998; Goodwin and Ross 1992), studies investigating the financial consequences of complaint handling are limited. This lack of research is particularly remarkable, given the significant amount of resources devoted to complaint-handling activities and the increasing pressure that marketing practitioners face to justify spending valuable firm resources and demonstrate the financial contribution of the marketing function 
to the bottom line (Kumar and Shah 2009; Rust, Lemon, and Zeithaml 2004). In this research, we help bridge this important gap by providing a framework for understanding the financial implications of complaint handling and by building a direct link between different organizational responses to complaints and customer profitability. The results of our study reveal that, despite warnings from prior research about the potential negative consequences of service failures for the development of the customer-firm relationship (Kaltcheva et al. 2013; Beverland et al. 2010; Grégoire and Fisher 2008; Zeelenberg and Pieters 2004; Hess et al. 2003), customer profitability can increase after a complaint if the firm properly implements complaint-resolution mechanisms (i.e. timeliness, compensation and communications).

To what extent. In this study, we provide an understanding of the differences in effectiveness of alternative complaint-handling initiatives. Prior research has provided some preliminary evidence about the heterogeneous nature of customer responses to complaint handling, showing that different complaint-resolution mechanisms produce highly heterogeneous responses from customers (Roschk and Gelbrich 2014; Homburg, Fürst, and Koschate 2010; Hess, Ganesan, and Klein 2003). In our research, we empirically corroborate this result and show that the effectiveness of timeliness, compensation and communications in increasing customer profitability differs significantly. Our study takes a step forward and provides a theoretical understanding of why different complaint-handling activities are differently effective at improving profitability. This research shows that the answer to this question lies in two important aspects. Firstly, different complaint-handling initiatives provide different types of benefits to customers (economic, social, or both -Berry 1995). Secondly, customers experience different types of losses after a failure episode. We show that the nature of the relationship (whether it is a strong or a weak relationship -Ringberg et al. 2007) and the type of failure experienced (whether it is economic or non-economic - Gelbrich and Roschk 2011) jointly determine the types of losses (whether economic, social, or both) that customers 
suffer after the failure situation and, thus, the types of benefits that they seek to recover from the losses. Notably, in contrast to prior research that investigates the moderating role of relationship strength (Wan, Hui, and Wyer 2011; Grégoire, Tripp, and Legoux 2009; Grégoire and Fisher 2006) and type of failure (Hess, Ganesan, and Klein 2003; Smith, Bolton, and Wagner 1999) in isolation, we study the simultaneous impact of these two variables. By considering them simultaneously, we offer new theoretical insights into the interplay between these two contingency variables and provide an understanding of the underlying forces that explain to what extent alternative complaint-handling initiatives are effective at improving profitability.

Under what circumstances. In this study, we show the values of the contingency variables (relationship strength and failure type) for which recovery efforts (timeliness, compensation, and communications) are most effective at improving profitability. The existence of different types of benefits provided by complaint-handling initiatives and of different types of benefits sought by customers under different values of the contingency variables provided the basis for the development of a congruency framework (Chandon, Wansink, and Laurent 2000). With this framework, we illustrate that the complaint-handling activities implemented by the firm and the two contingency variables interact in predictable ways to explain profitability depending on their level of congruency. Specifically, our study offers new theoretical insights into the circumstances that explain the heterogeneous responses to complaint handling by demonstrating that a high congruency between the benefits offered through complaint handling and the benefits sought by the customer enhances customer profitability. Interestingly, when customers experience both economic and social losses, the weight attached to each type of loss differs, and so does the response to complaint handling. Our study shows that losses caused by the nature of the relationship are given more weight than losses produced by the type of failure. This helps explain why customers are 
more responsive to complaint-handling activities that provide benefits that compensate the losses caused by framing the failure according to the nature of the relationship, and less responsive to other initiatives directed at compensating the losses caused by framing the failure in terms of the type of failure. In addition to providing a conceptual understanding of the differences in effectiveness of alternative complaint-handling efforts, our study may help better understand prior research findings. For example, Roschk and Gelbrich (2014) find that customers who suffer a non-economic failure (lack of attention -social loss) respond more favorably to a monetary compensation or to exchanged goods (economic benefit) than to a psychological compensation (social benefit). A possible explanation for this result is that these customers may desire a utilitarian (short-term) relationship with the firm (due to the experimental nature of the data collection, these customers do not feel that they have a strong relationship with the firm) and, thus, customer responses to complaint handling are more strongly driven by the nature of the relationship (seeking economic benefits) than by the type of failure (seeking social benefits).

Overall, by providing a unifying and integrative contingency framework based on the congruence approach, we offer a conceptual understanding of the underlying mechanisms that govern the effectiveness of complaint handling on financial measures.

\section{MANAGERIAL IMPLICATIONS}

As more and more customers become more demanding and the number of complaints increases, firms should devise new ways to manage them more effectively to obtain a positive return on their investments and enhance financial performance. In this study, we have conceptually proposed and empirically validated a framework that can be used by companies as a useful instrument to allocate their resources more adequately across alternative complaint-handling initiatives to increase profitability. 
A major conclusion from our study is that companies cannot approach customers using a standard complaint-handling strategy. We demonstrate that customers are highly heterogeneous with respect to their needs (i.e. benefits sought) after a service failure. Specifically, we show that the benefits that customers seek to recover from the losses produced by the failure are determined by the interaction between two critical factors: the nature of the relationship (as identified by the duration of the relationship with the firm) and the type of failure (whether the failure is economic or non-economic), which are frequently recorded in companies' databases. Companies can use this information to segment their complaining customers into the four segments identified theoretically and empirically in our research. This segmentation offers the basis for developing complaint-handling activities adapted to the needs of the customers in each segment in order to improve their effectiveness.

One of the major conclusions of the congruency framework proposed is that marketers can increase the effectiveness of complaint handling by matching the type of benefit provided through complaint handling with the type of benefit sought by customers in each segment. We show that different complaint-handling initiatives provide different types of benefits to customers. Thus, firms that provide a type of benefit (whether economic, social or both) that matches the type of benefit that the customers in each segment are seeking will see a substantial increase in the effectiveness of their complaint-handling efforts. Our findings also suggest how to approach customers when they experience both economic and social losses (segments 1 and 4). For these customers, in addition to providing a fast response (which provides both economic and social benefits), complaint-handling activities that offer benefits that compensate the loss produced by framing the failure according to the nature of the relationship are particularly effective. Therefore, our study offers practical guidance about how to prioritize the alternative complaint-handling initiatives to maximize the return on the investments. 
This study can also offer valuable insights to increase the effectiveness of complaint handling for companies that have established specific complaint-handling protocols, or for firms that, due to their limited resources, cannot respond to all complaint situations. For example, some companies may offer an automatic compensation in the event of any given complaint (e.g. service interruption, malfunctioning product, delayed delivery). The results of our study suggest that companies can obtain a higher return on their complaint-handling investments by prioritizing the segments of customers to which they offer this compensation. Our findings indicate that compensation produces a strong increase in profit for customers with weak relationships who suffer an economic failure. However, compensation can backfire when it is applied to customers with strong relationships who suffer a non-economic failure, producing significant profit reductions. Companies with limited resources can also benefit from these comparisons to identify for which segments each initiative produces the largest impact on profits, helping them to prioritize their interventions and allocate their resources more efficiently.

Finally, our customer profitability-based framework may help firms to make their marketing functions more financially accountable. As noted previously, in this study, we build a link between complaint handling and performance. With the help of our framework, the impact of alternative complaint-handling strategies can be analyzed in terms of their contribution to financial performance. Based on this analysis, the resources can then be allocated to the alternatives that provide the highest return on the investments (highest customer profitability) for each customer segment, helping companies justify spending valuable firm resources and demonstrating their contribution to the firm's growth.

\section{LIMITATIONS AND FUTURE RESEARCH}

This study presents a number of limitations which can be addressed by future research. First, we focus on financial services and consider a specific bank. Despite the significant and 
robust results that we obtain, given the particular characteristics of this market (high involvement, contractual relationship) and due to the use of a single company, the generalization of the study findings to other services industries and other companies must be carried out with care. Further research should evaluate and validate the conceptual framework in other industries.

Second, although we consider three central complaint-resolution mechanisms, timeliness, compensation and communications, prior research has identified additional factors that can influence customer reactions to complaint handling, including the attentiveness of employees and the credibility of their behavior. Moreover, we have only focused on the linear effects of these actions, and considered customers who have complained only once. However, prior studies have suggested that the relationships between complaint handling and consumer responses may be more complex than currently thought (Zhou et al. 2014; Davidow 2003), and that prior complaint histories can also contribute to explaining current customer reactions to complaint handling (Joireman, Grégoire, Devezer, and Tripp 2013). An interesting avenue for future research would be to study potential non-linear effects and consider the role of prior complaints. In addition, the effectiveness of these strategies may be moderated by factors such as the level of customer switching costs or customer involvement with the category of products under study. Future research can investigate the relative importance of these factors in understanding the consequences of complaint-handling activities on customer profitability.

Finally, in this study, we focus on organizational responses to customer complaints. However, there may be situations in which customers experience a service failure and do not file a complaint. Future research should try to identify these customers and examine the financial return in terms of customer profitability of initiating proactive actions directed at addressing the problem. In addition, after a service failure, the customer may become more predisposed to switch to alternative suppliers. Thus, competitive actions can interfere in the 
effectiveness of the complaint-handling strategies initiated by the firm. Due to the lack of competitive information, we have not been able to examine these effects. However, a promising avenue for future research would be to investigate competitive activity and its direct and moderating role on the effectiveness of organizational responses to customer complaints. 


\section{ACKNOWLEDGEMENTS}

The authors are members of the research group "Generes" (http://generes.unizar.es/en/), and they appreciate the financial support received from the projects ECO2011-23027 (MICINN, FEDER), and S09-PM062 (Spanish Regional Government of Aragón), as well as from the program “Ayudas a la Investigación en Ciencias Sociales, Fundación Ramón Areces”. Iguacel Melero gratefully acknowledges the financial aid from the Spanish government (Ministry of Education) through the FPU scholarship program (AP2010-4448). The authors' names appear in alphabetical order. 


\section{REFERENCES}

Andrews, Rick L., and Imran S. Currim (2003), "Retention of latent segments in regressionbased marketing models," International Journal of Research in Marketing, 20 (4), 315 321.

Barnes, James G. (1997), "Closeness, strength, and satisfaction: Examining the nature of relationships between providers of financial services and their retail customers," Psychology \& Marketing, 14 (8), 765-790.

Berry, Leonard L. (1995), "Relationship marketing of services-growing interest, emerging perspectives," Journal of the Academy of Marketing Science, 23 (4), 236-245.

Beverland, Michael B., Steven M. Kates, Adam Lindgreen, and Emily Chung (2010), "Exploring consumer conflict management in service encounters," Journal of the Academy of Marketing Science, 38 (5), 617-633.

Bolton, Ruth N., Katherine N. Lemon, and Peter C. Verhoef (2004), "The Theoretical Underpinnings of Customer Asset Management: A Framework and Propositions for future research,” Journal of the Academy of Marketing Science, 32 (3), 271-292.

Boshoff, Christo (1997), “An experimental study of service recovery options,” International Journal of Service Industry Management, 8 (2), 110-130.

Brady, Michael K., J. Joseph Cronin, Gavin L. Fox, and Michelle L. Roehm (2008), "Strategies to offset performance failures: The role of brand equity," Journal of Retailing, 84 (2), 151-164.

Chandon, Pierre, Brian Wansink, and Gilles Laurent (2000), “A benefit congruency framework of sales promotion effectiveness," Journal of Marketing, 64 (October), 6581.

Data Monitor (2012), Available at:

http://www.datamonitor.com/store/News/reputation_is_vital_for_success_in_banking? productid=2D5EF715-3D7B-4B32-8A91-72DFC057280F

Davidow, Moshe (2003), “Organizational Responses to Customer Complaints: What Works and What Doesn't," Journal of Service Research, 5 (3), 225-250.

DeWitt, Tom, Doan T. Nguyen, and Roger Marshall (2008), "Exploring Customer Loyalty Following Service Recovery The Mediating Effects of Trust and Emotions,” Journal of Service Research, 10 (3), 269-281.

Dias, José G., and Jeroen K. Vermunt (2007), “Latent Class Modelling of Website Users' Search Patterns: Implications for Online Market Segmentation,” Journal of Retailing and Consumer Services, 14 (6), 359-368. 
EPSI Rating (2012). Available at: http://www.epsi-rating.com/

Estelami, Hooman (2000), "Competitive and Procedural Determinants of Delight and Disappointment in Consumer Complaint Outcomes," Journal of Service Research, 2 (3), 285-300.

Estelami, Hooman (2003), "Sources, characteristics, and dynamics of post-purchase price complaints," Journal of Business Research, 56 (5), 411-419.

European Consumer Centres Network (ECC-Net), “The European Online Marketplace," Consumer Complaints 2010-2011. Publications of the European Union. September, 2012.

European Consumer Centres Network (ECC-Net), “Get Help and Advice on your Purchase Abroad," 2011 Annual Report. Publications of the European Union, 2012.

Gelbrich, Katja (2010), “Anger, frustration, and helplessness after service failure: coping strategies and effective informational support," Journal of the Academy of Marketing Science, 38 (5), 567-585.

Gelbrich, Katja, and Holger Roschk (2011), “A meta-analysis of organizational complaint handling and customer responses," Journal of Service Research, 14 (1), 24-43.

Goodman, John (2006), "Manage complaints to enhance loyalty," Quality Progress, 39 (2), 28-34.

Goodwin, Cathy, and Ivan Ross (1992), "Consumer responses to service failures: influence of procedural and interactional fairness perceptions," Journal of Business Research, 25 (2), 149-163.

Grégoire, Yany, Thomas M. Tripp, and Renaud Legoux (2009), "When Customer Love Turns into Lasting Hate: The Effects of Relationship Strength and Time on Customer Revenge and Avoidance," Journal of Marketing, 73 (6), 18-32.

Grégoire, Yany, and Robert J. Fisher (2008), "Customer betrayal and retaliation: when your best customers become your worst enemies," Journal of the Academy of Marketing Science, 36 (2), 247-261.

Grégoire, Yany, and Robert J. Fisher (2006), “The effects of relationship quality on customer retaliation," Marketing Letters, 17 (1), 31-46.

Grewal, Dhruv, Anne L. Roggeveen, and Michael Tsiros (2008), "The Effect of Compensation on Repurchase Intentions in Service Recovery," Journal of Retailing, 84 (4), 424-434. 
Gupta, Sachin, and Pradeep K. Chintagunta (1994), “On Using Demographic Variables to Determine Segments Membership in Logit Mixture Models," Journal of Marketing Research, 31 (1), 128-136.

Hess, Ronald, Shankar Ganesan, and Noreen Klein (2003), "Service failure and recovery: the impact of relationship factors on customer satisfaction," Journal of the Academy of Marketing Science, 31 (2), 127-145.

Homburg, Christian, Andreas Fürst, and Nicole Koschate (2010), "On the importance of complaint handling design: a multi-level analysis of the impact in specific complaint situations," Journal Academy of Marketing Science, 38 (3), 265-287.

Homburg, Christian, and Andreas Fürst (2005), "How organizational Complaint handling drives customer loyalty: an analysis of the mechanistic and the organic approach," Journal of Marketing, 69 (July), 95-114.

Huang, Wen-Hsien, and Tzu-Da Lin (2011), "Developing effective service compensation strategies: is a price reduction more effective than a free gift?," Journal of Service Management, 22 (2), 202-216.

Johnson, Allison R., Maggie Matear, and Matthew Thomson (2011), "A Coal in the Heart: Self-Relevance as a Post-Exit Predictor of Consumer Anti-Brand Actions," Journal Consumer Research, 38 (1), 108-125.

Joireman, Jeff, Yany Grégoire, Berna Devezer, and Thomas M. Tripp (2013), "When do customers offer firms a "second chance" following a double deviation? The impact of inferred firm motives on customer revenge and reconciliation," Journal of Retailing, 89 (3), 315-337.

Kaltcheva, Velitchka D., Robert D. Winsor, and A. Parasuraman (2013), "Do customer relationships mitigate or amplify failure responses?,” Journal of Business Research, 66 (4), 525-532.

Keaveney, Susan M. (1995), "Customer Switching Behavior in Service Industries: An Exploratory Study,” Journal of Marketing, 59 (April), 71-82.

Kelley, Scott W., K. Douglas Hoffman, and Mark A. Davis (1993), “A typology of retail failures and recoveries," Journal of Retailing, 69 (4), 429-452.

Kumar, V., and Denish Shah (2009), "Expanding the role of marketing: from customer equity to market capitalization," Journal of Marketing, 73 (6), 119-136.

Lewis, Barbara R., and Sotiris Spyrakopoulos (2001), "Service failures and recovery in retail banking: the customers' perspective,” International Journal of Bank Marketing, 19 (1), $37-48$. 
Liao, Hui (2007), "Do it right this time: the role of employee service recovery performance in customer-perceived justice and customer loyalty after service failures," Journal of Applied Psychology, 92 (2), 475-489.

Mahajan, Jayashree, and Gilbert A. Churchill Jr. (1988), "An Investigation into Alternative Contingency Approaches of Organizing the Selling Function," Working Paper. University of Wisconsin-Madison.

Mittal, Vikas, John W. Huppertz and Adwait Khare (2008), "Customer complaining: the role of tie strength and information control," Journal of Retailing, 84 (2), 195-204.

Mohr, Jakki, and John R. Nevin (1990), “Communication Strategies in Marketing Channels: A Theoretical Perspective,” Journal of Marketing, 54 (October), 36-51.

Purohit, Devavrat, and Joydeep Srivastava (2001), "Effect of manufacturer reputation, retailer reputation, and product warranty on consumer judgments of product quality: a cue diagnosticity framework," Journal of Consumer Psychology, 10 (3), 123-134.

Reinartz, Werner J., and V. Kumar (2003), "The impact of customer relationship characteristics on profitable lifetime duration,” Journal of Marketing, 67 (January), 7799.

Ringberg, Torsten, Gaby Odekerken-Schröder, and Glenn Christensen (2007), “A cultural models approach to service recovery,” Journal of Marketing, 71 (July), 194-214.

Roschk, Holger, and Katja Gelbrich (2014), "Identifying Appropriate Compensation Types for Service Failures: A Meta-Analytic and Experimental Analysis," Journal of Service Research, 17 (2), 195-211.

Rust, Roland, Katherine N. Lemon, and Valarie A. Zeithaml (2004), "Return on Marketing: Using Customer Equity to Focus Marketing Strategy," Journal of Marketing, 68 (January), 109-128.

Slovic, Paul, and Sarah Lichtenstein (1971), "Comparison of Bayesian and regression approaches to the study of information processing in judgment," Organizational Behavior and Human Performance, 6 (6), 649-744.

Smith, Amy K., and Ruth N. Bolton (1998), “An experimental investigation of customer reactions to service failure and recovery encounters: paradox or peril?," Journal of Service Research, 1 (1), 65-81.

Smith, Amy K., Ruth N. Bolton, and Janet Wagner (1999), “A model of customer satisfaction with service encounters involving failure and recovery," Journal of Marketing Research, 36 (August), 356-372. 
Surachartkumtonkun, Jiraporn, Paul G. Patterson, and Janet R. McColl-Kennedy (2013), "Customer rage back-story: linking needs-based cognitive appraisal to service failure," Journal of Retailing, 89 (1), $72-87$.

Tax, Stephen S., Stephen W. Brown, and Murali Chandrashekaran (1998), "Customer evaluations of service complaint experiences: implications for relationship marketing," Journal of Marketing, 62 (April), 60-76.

Valenzuela, Fredy-Roberto, and Ray Cooskey, R. (2012), “Customer Perception of Time and Complaint Outcome during the Service Recovery Process," International Review of Business Research Papers, 8 (4), 1-19.

Van Vaerenbergh, Yves, Bart Lariviere, and Iris Vermeir (2012), "The Impact of Process Recovery Communications on Customer Satisfaction, Repurchase Intentions and Word of Mouth Intentions," Journal of Service Research, 15 (3), 262-279.

Venkatesan, Rajkumar, and V. Kumar (2004), “A Customer Lifetime Value Framework for Customer Selection and Resource Allocation Strategy," Journal of Marketing, 68 (October), 106-25.

Wan, Lisa C., Michael K. Hui, and Robert S. Wyer Jr. (2011), “The role of relationship norms in responses to service failures," Journal of Consumer Research, 38 (2), 260-277.

Wieringa, Jaap E., and Peter C. Verhoef (2007), "Understanding Customer Switching Behavior in a Liberalizing Service Market: An Exploratory Study," Journal of Service Research, 10 (2), 174-186.

Zeelenberg, Marcel, and Rik Pieters (2004), "Beyond valence in customer dissatisfaction: a review and new findings on behavioural responses to regret and disappointment in failed services," Journal of Business Research, 57 (4), 445-455.

Zhou, Yuanyuan, Alex S. Tsang, Minxue Huang, and Nan Zhou (2014), "Does delaying service-failure resolution ever make sense?" Journal of Business Research, 67 (2), 159-166.

Zhu, Zhen, Cheryl Nakata, Sivakumar, K., and Dhruv Grewal (2013), "Fix it or leave it? Customer recovery from self-service technology failures," Journal of Retailing, 89 (1), $15-29$. 
FIGURE 1:

CONCEPTUAL FRAMEWORK: A CONGRUENCY FRAMEWORK OF COMPLAINT HANDLING EFFECTIVENESS

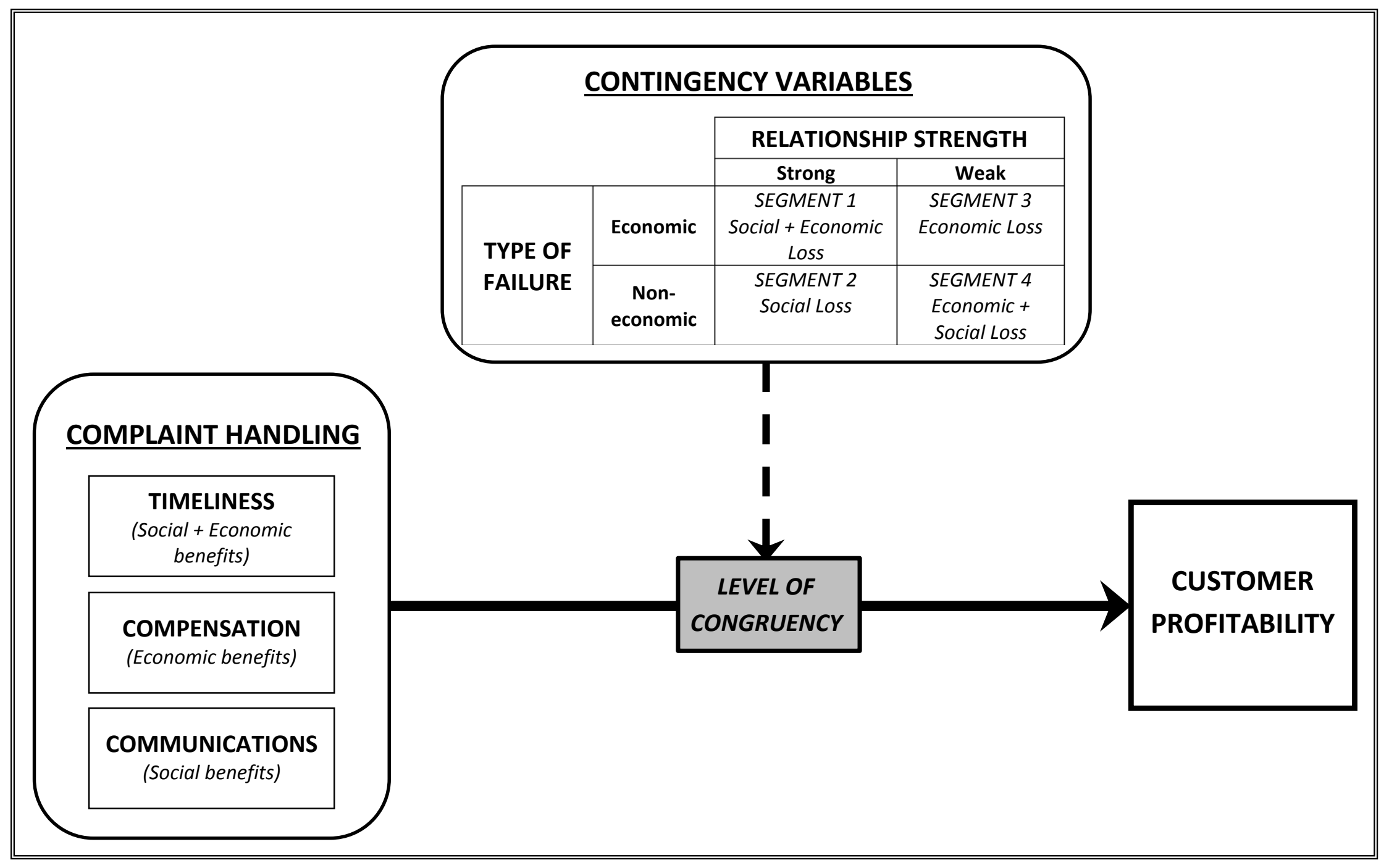


FIGURE 2:

LONGITUDINAL ANALYSIS

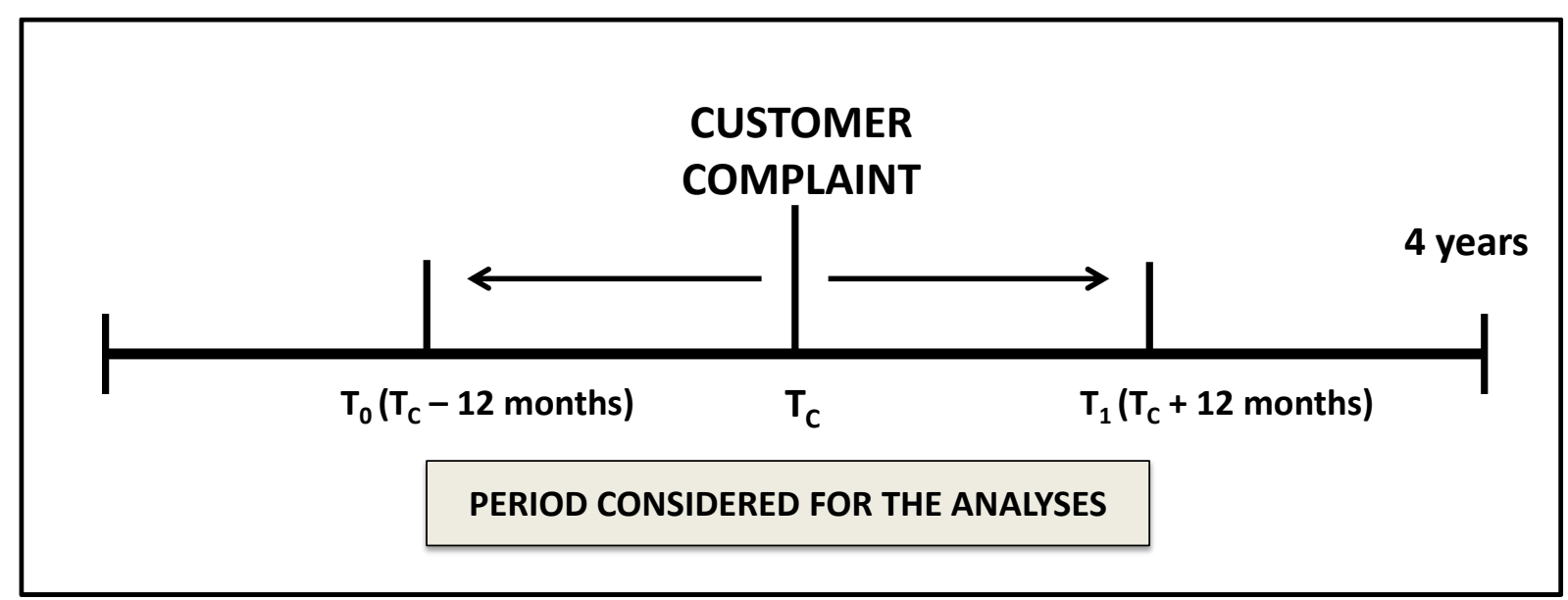


TABLE 1:

RESEARCH HYPOTHESES: EFFECT OF COMPLAINT HANDLING ON CUSTOMER PROFITABILITY

\begin{tabular}{|c|c|c|c|c|}
\hline \multirow{2}{*}{ Hypothesis } & \multirow{2}{*}{ Segment } & \multicolumn{3}{|c|}{ Complaint-handling initiatives } \\
\hline & & Timeliness & Compensation & Communications \\
\hline HO & All segments & Positive & Positive & Positive \\
\hline H1 & $\begin{array}{c}\text { Segment 1 } \\
\text { Strong Relationship and } \\
\text { Economic Failure }\end{array}$ & +++ & + & ++ \\
\hline H2 & $\begin{array}{c}\text { Segment } 2 \\
\text { Strong Relationship and Non- } \\
\text { economic Failure }\end{array}$ & ++ & + & +++ \\
\hline $\mathbf{H 3}$ & $\begin{array}{c}\text { Segment } \mathbf{3} \\
\text { Weak Relationship and } \\
\text { Economic Failure }\end{array}$ & ++ & +++ & + \\
\hline H4 & $\begin{array}{c}\text { Segment } \mathbf{4} \\
\text { Weak relationship and Non- } \\
\text { economic Failure }\end{array}$ & +++ & ++ & + \\
\hline H5 & $\begin{array}{l}\text { Effectiveness of complaint } \\
\text { handling across segments }\end{array}$ & $\begin{array}{l}\text { H5a: Stronger for } \\
\text { segments } 1 \text { and } 4\end{array}$ & $\begin{array}{l}\text { H5b: Stronger for } \\
\text { segments } 3 \text { and } 4\end{array}$ & $\begin{array}{l}\text { H5a: Stronger for } \\
\text { segments } 2 \text { and } 1\end{array}$ \\
\hline
\end{tabular}

Note: Number of + indicates strength of relationship with customer profitability. A higher number of + is indicative of a stronger relationship; a lower number of + is indicative of a weaker relationship. 
TABLE 2:

\section{VARIABLE MEASUREMENT AND DESCRIPTIVE STATISTICS}

\begin{tabular}{|c|c|c|c|c|}
\hline & Variables & Description & Mean & $\begin{array}{c}\text { Standard } \\
\text { Desviation }\end{array}$ \\
\hline $\begin{array}{l}\text { Dependent } \\
\text { variable }\end{array}$ & Customer profitability & $\begin{array}{l}\text { Difference (in thousands of euros) between customer profitability (difference between } \\
\text { customer revenues and costs) of customer i in periods } \mathrm{T}_{1} \text { (one year after the complaint) and } \\
\mathrm{T}_{0} \text { (one year before the complaint). }\end{array}$ & 1.78 & 33.48 \\
\hline \multirow{3}{*}{$\begin{array}{l}\text { Organizational } \\
\text { responses to } \\
\text { complaints }\end{array}$} & Timeliness & $\begin{array}{l}1 \text { divided by the number of days that it takes the bank to respond to the complaint filed by } \\
\text { customer } i \text {. }\end{array}$ & 0.0442 & 0.1099 \\
\hline & Compensation & $\begin{array}{l}\text { Amount of money (in euros) provided by the bank to customer i to recover from the } \\
\text { problem. }\end{array}$ & 46.02 & 404.39 \\
\hline & Communications & $\begin{array}{l}\text { Dummy variable which takes the value } 1 \text { when the firm offers an explanation and an } \\
\text { apology to the customer after the complaint, and } 0 \text { otherwise. }\end{array}$ & 0.87 & 0.34 \\
\hline \multirow{5}{*}{$\begin{array}{l}\text { Control } \\
\text { variables }\end{array}$} & Direct Marketing & $\begin{array}{l}\text { Difference in the total number of direct marketing actions (direct mail and telephone calls) } \\
\text { directed to customer } \mathrm{i} \text { between periods } \mathrm{T}_{1} \text { (one year after the complaint) and } \mathrm{T}_{0} \text { (one year } \\
\text { before the complaint). }\end{array}$ & 0.10 & 2.09 \\
\hline & Age & Age (in years) of customer i at the moment she/he filed the complaint. & 55.64 & 13.04 \\
\hline & Income & $\begin{array}{l}\text { Measured with } 3 \text { categories: (1) salary below } 24,000 € \text { per year, (2) salary between } 24,000 \\
\text { and } 45,000 € \text { per year; (3) salary above } 45,000 € \text { per year. }\end{array}$ & 2.27 & 0.62 \\
\hline & Gender & Dummy variable which takes the value 1 for men and 0 for women. & 0.67 & 0.47 \\
\hline & $\begin{array}{l}\text { Customer profitability } \\
\text { before the failure }\end{array}$ & Customer profitability (in thousands of euros) of customer i before the observation period. & 31.08 & 40.35 \\
\hline \multirow{2}{*}{$\begin{array}{l}\text { Contingency } \\
\text { variables }\end{array}$} & Relationship strength & $\begin{array}{l}\text { Length of time (in years) that customer i has been customer of the bank at the moment } \\
\text { she/he filed the complaint. }\end{array}$ & 22.8 & 12.74 \\
\hline & Type of failure & $\begin{array}{l}\text { Dummy variable which takes the value } 1 \text { when customer i experiences an economic failure } \\
\text { and } 0 \text { when the service failure is non-economic. }\end{array}$ & 0.58 & 0.49 \\
\hline
\end{tabular}


TABLE 3:

\section{CORRELATION MATRIX}

\begin{tabular}{|c|c|c|c|c|c|c|c|c|c|c|c|c|}
\hline & Variables & 1 & 2 & 3 & 4 & 5 & 6 & 7 & 8 & 9 & 10 & 11 \\
\hline Dependent variable & 1. Customer Profitability & 1 & & & & & & & & & & \\
\hline \multirow{3}{*}{$\begin{array}{l}\text { Organizational } \\
\text { responses to } \\
\text { complaints }\end{array}$} & 2. Timeliness & 0.007 & 1 & & & & & & & & & \\
\hline & 3. Compensation & 0.088 & -0.012 & 1 & & & & & & & & \\
\hline & 4. Communications & 0.014 & 0.137 & 0.001 & 1 & & & & & & & \\
\hline \multirow{5}{*}{$\begin{array}{c}\text { Control } \\
\text { Variables }\end{array}$} & 5. Direct Marketing & -0.008 & -0.001 & 0.036 & 0.038 & 1 & & & & & & \\
\hline & 6. Age & -0.191 & -0.027 & 0.031 & -0.063 & -0.082 & 1 & & & & & \\
\hline & 7. Income & 0.074 & 0.049 & 0.058 & 0.069 & -0.068 & 0.053 & 1 & & & & \\
\hline & 8. Gender & 0.002 & 0.030 & 0.006 & -0.105 & -0.012 & 0.048 & -0.046 & 1 & & & \\
\hline & $\begin{array}{l}\text { 9. Customer profitability } \\
\text { before the failure }\end{array}$ & -0.199 & 0.008 & 0.007 & 0.076 & -0.010 & 0.013 & 0.263 & 0.019 & 1 & & \\
\hline \multirow{2}{*}{$\begin{array}{l}\text { Contingency } \\
\text { variables }\end{array}$} & 10. Relationship Strength & -0.215 & -0.020 & -0.031 & -0.082 & -0.059 & 0.233 & -0.026 & -0.043 & 0.086 & 1 & \\
\hline & 11. Type of Failure & 0.032 & -0.056 & 0.076 & -0.029 & -0.107 & -0.048 & -0.053 & 0.068 & -0.067 & -0.011 & 1 \\
\hline
\end{tabular}


TABLE 4:

FIT STATISTICS FOR DIFFERENT SEGMENT SOLUTIONS IN LATENT CLASS MODEL

\begin{tabular}{cccc}
\hline Number of Classes & Log Likelihood & BIC & AIC3 \\
\hline $\mathbf{1}$ & -3828.07 & 7731.52 & 7684.27 \\
$\mathbf{2}$ & -3256.12 & 6683.41 & 6587.16 \\
$\mathbf{3}$ & -3139.54 & $\mathbf{6 5 2 9 . 8 7}$ & 6386.75 \\
$\mathbf{4}$ & -3057.17 & 6544.33 & $\mathbf{6 2 5 0 . 8 4}$ \\
$\mathbf{5}$ & -3025.60 & 6575.25 & 6254.42 \\
\hline
\end{tabular}

Note: $\mathrm{BIC}=$ Bayesian Information Criterion; AIC3= Akaike Information Criterion with a per parameter penalty factor of three. The smallest values of BIC and AIC3 are highlighted. 
TABLE 5:

ESTIMATION RESULTS OF THE LATENT CLASS MODEL FOR THE FOUR-SEGMENT SOLUTION

\begin{tabular}{|c|c|c|c|c|c|c|c|}
\hline \multirow[b]{2}{*}{ Independent variables } & \multicolumn{4}{|c|}{ Customer heterogeneity } & \multirow[b]{2}{*}{ P-value } & \multirow[b]{2}{*}{ Wald $(=)$ test } & \multirow[b]{2}{*}{ P-value } \\
\hline & $\begin{array}{c}\text { Class } 1 \\
(\mathrm{SR}-\mathrm{EF})\end{array}$ & $\begin{array}{c}\text { Class } 2 \\
\text { (SR-NEF) }\end{array}$ & $\begin{array}{c}\text { Class } 3 \\
(\mathrm{WR}-\mathrm{EF})\end{array}$ & $\begin{array}{c}\text { Class } 4 \\
\text { (WR-NEF) }\end{array}$ & & & \\
\hline Intercept & $12.5442^{* * *}$ & $14.252^{* * * *}$ & $20.7421^{* * * *}$ & $2.0056 * * *$ & $\mathrm{p}<\mathbf{0 . 0 1}$ & 28.7411 & $\mathrm{p}<0.01$ \\
\hline \multicolumn{8}{|c|}{ Organizational responses to complaints } \\
\hline Timeliness & $4.2667^{* * *}$ & $0.2541^{*}$ & $\mathbf{7 . 5 9 8 2}^{* * * *}$ & $0.2296 * *$ & $\mathrm{p}<0.01$ & 13.0833 & $\mathrm{p}<0.01$ \\
\hline Compensation & $0.2973^{*}$ & $-1.3352^{*}$ & $17.2143^{* * * *}$ & $0.4122^{* * * *}$ & $\mathbf{p}<\mathbf{0 . 0 1}$ & 25.1614 & $\mathrm{p}<0.01$ \\
\hline Communications & $2.7612^{* * *}$ & $2.5361^{* * * *}$ & $2.2419^{* * *}$ & 0.3075 & $\mathrm{p}<0.05$ & 9.9260 & $\mathrm{p}<\mathbf{0 . 0 5}$ \\
\hline \multicolumn{8}{|l|}{ Control variables } \\
\hline Profitability before failure & $-8.7451^{* *}$ & $3.3242^{* *}$ & $-1.2879^{*}$ & -0.1672 & $\mathbf{p}<0.01$ & 24.5973 & $\mathrm{p}<0.01$ \\
\hline Direct Marketing & $4.9984^{* * *}$ & $6.3275^{* * * *}$ & $2.1643^{*}$ & 0.0240 & $\mathbf{p}<0.01$ & 11.5591 & $\mathrm{p}<0.01$ \\
\hline Age & $2.7812^{* *}$ & $-5.4676^{* *}$ & $13.5128^{* * *}$ & -0.4777 & $\mathrm{p}<0.01$ & 22.9583 & $\mathbf{p}<0.01$ \\
\hline Income (1) & $-8.3035^{*}$ & -0.8874 & $5.2117^{* * * *}$ & -0.1985 & & & \\
\hline Income (2) & 2.4128 & $2.4152^{* *}$ & -0.4765 & -1.4266 & $\mathbf{p}<0.01$ & 13.3725 & $\mathbf{p}<\mathbf{0 . 0 1}$ \\
\hline Income (3) & $3.0425^{* * *}$ & -3.5267 & -3.7948 & $0.2454^{*}$ & \multirow{3}{*}{$\mathbf{p}<\mathbf{0 . 1 0}$} & \multirow{3}{*}{9.4754} & \\
\hline Gender (1) & $4.2354^{* * * *}$ & -0.7054 & $2.9852^{* *}$ & -0.0831 & & & \multirow{2}{*}{$\mathbf{p}<0.05$} \\
\hline Gender (0) & $-4.2354^{* * *}$ & 0.7054 & $-2.9852^{* *}$ & 0.0831 & & & \\
\hline \multicolumn{8}{|c|}{ Contingency variables: segment characterization } \\
\hline Relationship strength & $0.5744^{* * * *}$ & $0.2968^{* * * *}$ & $0.1633^{* * * *}$ & $0.0942^{* *}$ & $\mathrm{p}<0.01$ & & \\
\hline Economic failure & $0.1970^{* * *}$ & $-0.2741^{* * * *}$ & $0.1105^{* *}$ & $-0.0781^{*}$ & \multirow{2}{*}{$\mathrm{p}<0.10$} & & \\
\hline Non-economic failure & $-0.1970^{* * *}$ & $0.2741^{* * * *}$ & $-0.1105^{* *}$ & $0.0781^{*}$ & & & \\
\hline
\end{tabular}

Note: significant parameters highlighted in bold: ${ }^{* * *} \mathrm{p}<0.01 ;{ }^{* *} \mathrm{p}<0.05 ;{ }^{*} \mathrm{p}<0.10$. 


\section{TABLE 6:}

\section{HYPOTHESIS TESTING RESULTS}

\begin{tabular}{|c|c|c|c|c|}
\hline Hypothesis & Segment & Hypothesized effect & Study findings & $\begin{array}{l}\text { Hypothesis } \\
\text { testing }\end{array}$ \\
\hline HO & All segments & $\begin{array}{l}\text { Positive effect of complaint handling } \\
\text { on customer profitability }\end{array}$ & $\begin{array}{c}10 \text { out of } 12 \text { parameters are positive } \\
\text { and significant }\end{array}$ & $\begin{array}{l}\text { Mostly } \\
\text { supported }\end{array}$ \\
\hline H1 & $\begin{array}{l}\text { Segment } 1 \\
\text { (SR-EF) }\end{array}$ & $\begin{array}{l}\text { 1. Timeliness }(+++) \\
\text { 2. Communications }(++) \\
\text { 3. Compensation }(+)\end{array}$ & $\begin{array}{l}\text { 1. Timeliness }(+++) \\
\text { 2. Communications }(++) \\
\text { 3. Compensation }(+)\end{array}$ & Supported \\
\hline $\mathbf{H 2}$ & $\begin{array}{l}\text { Segment } 2 \\
(\text { SR-NEF) }\end{array}$ & $\begin{array}{l}\text { 1. Communications }(+++) \\
\text { 2. Timeliness }(++) \\
\text { 3. Compensation }(+)\end{array}$ & $\begin{array}{l}\text { 1. Communications }(+++) \\
\text { 2. Timeliness }(++) \\
\text { 3. Compensation }(-)\end{array}$ & Supported \\
\hline H3 & $\begin{array}{l}\text { Segment } 3 \\
\text { (WR-EF) }\end{array}$ & $\begin{array}{l}\text { 1. Compensation }(+++) \\
\text { 2. Timeliness }(++) \\
\text { 3. Communications }(+)\end{array}$ & $\begin{array}{l}\text { 1. Compensation }(+++) \\
\text { 2. Timeliness }(++) \\
\text { 3. Communications }(+)\end{array}$ & Supported \\
\hline H4 & $\begin{array}{l}\text { Segment } 4 \\
(\text { WR-NEF) }\end{array}$ & $\begin{array}{l}\text { 1. Timeliness }(+++) \\
\text { 2. Compensation }(++) \\
\text { 3. Communications }(+)\end{array}$ & $\begin{array}{l}\text { 1. Compensation }(++) \\
\text { 2. Timeliness }(+)\end{array}$ & $\begin{array}{l}\text { Not } \\
\text { supported }\end{array}$ \\
\hline H5 & $\begin{array}{l}\text { Effectiveness } \\
\text { across } \\
\text { segments }\end{array}$ & $\begin{array}{c}\text { Timeliness: } S 1 \& S 4>S 2 \& S 3 \\
\text { Compensation: } S 3>S 4>S 1 \& S 2 \\
\text { Communications: } S 2>S 1>S 3 \& S 4\end{array}$ & $\begin{array}{c}\text { Timeliness: } S 3>S 1>S 2 \& S 4 \\
\text { Compensation: } S 3>S 4>S 1>S 2 \\
\text { Communications: } S 1 \& S 2 \& S 3>S 4\end{array}$ & $\begin{array}{l}\text { Mixed } \\
\text { support }\end{array}$ \\
\hline
\end{tabular}

